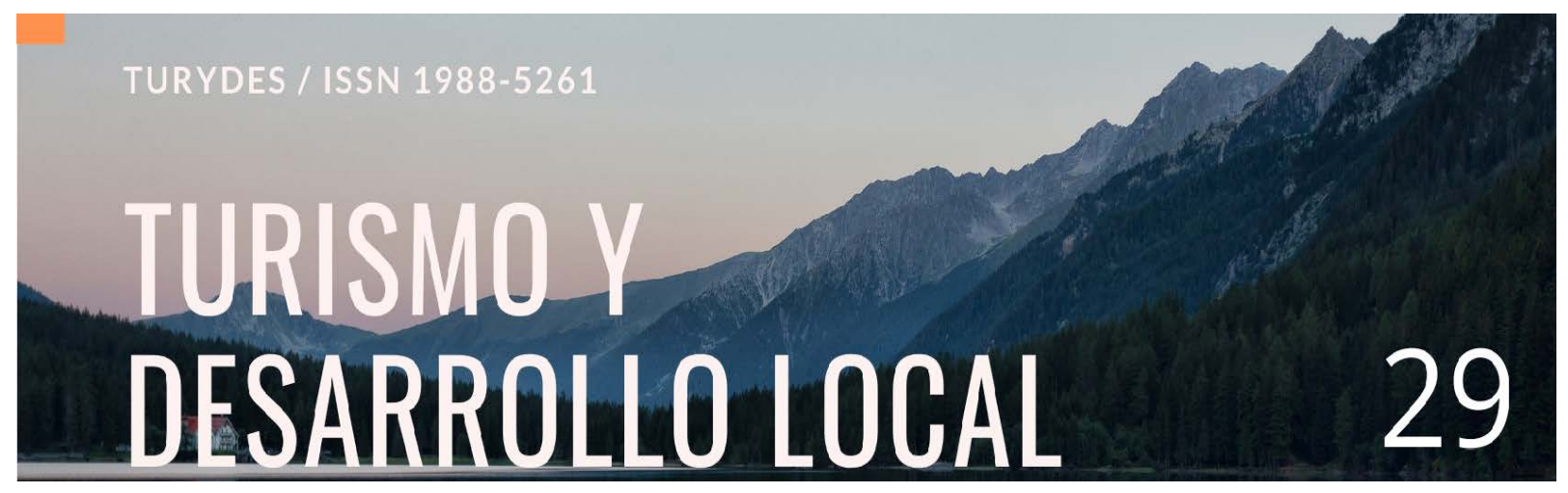

\title{
LA CALIDAD VISUAL PATRIMONIAL DEL PAISAJE AGRÍCOLA DEL ÁREA METROPOLITANA DE MENDOZA y EL TURISMO SUSTENTABLE
}

Dra. Arq. Manzini Marchesi Lorena ${ }^{i}$ INCIHUSA CONICET, CCT CONICET Mendoza

Imanzini@mendoza-conicet.gob.ar

Para citar este artículo puede utilizar el siguiente formato:

Manzini Marchesi Lorena: "La calidad visual patrimonial del paisaje agrícola del área metropolitana de Mendoza y el turismo sustentable", Revista Turydes: Turismo y Desarrollo, n. 29 (diciembre/dezembro 2020). En línea:

https://www.eumed.net/es/revistas/turydes/vol-13-no-29-diciembre-dezembro-2020/paisaje-agricolamendoza

\section{Resumen:}

La degradación paulatina que se observa desde fines del siglo XX en el paisaje agrícola del Área Metropolitana de Mendoza (AMM) es agravada por los efectos de la metropolización y tendencias locales de apropiación del territorio afectando su cualidad de recurso turístico provincial e internacional. En este marco sostenemos como hipótesis que el reconocimiento de los valores visuales del paisaje en conjunción a su dimensión histórica permite ordenar de forma adecuada la implantación de determinados usos y actividades turísticas en un territorio, contribuyendo de esta manera, con un turismo sustentable que promueva un desarrollo local. Para ello se analizará la calidad visual patrimonial en relación a la dimensión histórica del paisaje agrícola del Área Metropolitana de Mendoza. Entendemos por calidad visual patrimonial al grado de excelencia de los atributos visuales de las características físicas e históricas del paisaje. Su análisis conjuga el estudio histórico - temporal, con el de homogeneidad y rareza de los usos del suelo, los sistemas estructurantes, la visibilidad, la calidad visual e intervisibilidad en las unidades visuales patrimoniales del paisaje en estudio. Para ello se aplica una metodología de investigación interdisciplinaria que integra la disciplina histórica, arquitectónica y geográfica. Lo que permite el trabajo con fuentes documentales gráficas de diversas épocas del paisaje y sus elementos constitutivos, sumado a la información que brinda el paisaje desde los puntos de observación seleccionados en el territorio del AMM focalizados en los departamentos de Maipú y Luján de Cuyo. 
Palabras clave: Calidad visual del paisaje, Paisaje agrícola, Turismo sustentable, Percepción del paisaje, Dimensión histórica.

\section{THE HERITAGE VISUAL QUALITY OF THE AGRICULTURAL LANDSCAPE OF THE MENDOZA METROPOLITAN AREA AND SUSTAINABLE TOURISM}

\section{Abstract:}

The gradual degradation that has been observed since the end of the 20th century in the agricultural wine landscape of the Metropolitan Area of Mendoza (AMM) is aggravated by the effects of the metropolitanization and local tendencies of appropriation of the territory affecting its quality of provincial and international tourist resource. In this framework we hypothesize that the recognition of the visual values of the landscape in conjunction with its historical dimension allows for the proper ordering of the implementation of certain tourist uses and activities in a territory, thus contributing to sustainable tourism that promotes a local development. For this, the visual quality of heritage will be analyzed in relation to the historical dimension of the agricultural landscape of the Mendoza Metropolitan Area. By heritage visual quality we understand the degree of excellence of the visual attributes of the physical and historical characteristics of the landscape. The analysis combines the historical study of the landscape, with the homogeneity and rarity of land uses, structuring systems, visibility, visual quality and intervisibility in the heritage visual units of the landscape under study. For this, an interdisciplinary research methodology is applied that integrates the historical, architectural and geographical disciplines. This allows working with graphic documentary sources from various periods of the landscape and its constitutive elements, with the information provided by the landscape from the selected observation points in the territory of the AMM focused on the departments of Maipú and Luján de Cuyo.

Keywords: visual landscape quality, agricultural landscape, sustainable tourism, landscape perception, historical dimension.

\section{1- INTRODUCCIÓN ii}

El paisaje agrícola del Área Metropolitana de Mendoza (AMM) Argentina es un paisaje activo, dinámico y posee un carácter distintivo de valor patrimonial en el que se integran sus etapas históricas, y a su vez es un espacio en tensión producto de diversas percepciones, intereses y acciones efectuadas por los diversos actores que se vinculan a él. La resultante es una degradación paulatina desde fines del siglo XX que es agravada por los efectos de la metropolización y tendencias locales de apropiación del territorio afectando su cualidad de recurso turístico provincial e internacional.

El AMM, integra los departamentos de Capital, Las Heras, Guaymallén, Godoy Cruz, Luján de Cuyo y Maipú y se localiza en el Oasis Norte de Mendoza. Este último, integra la región vitivinícola denominada Zona Alta del Río Mendoza y la región Norte vitivinícola mendocina. Abraham (2000) manifiesta que el AMM es una concentración económica y demográfica típica de los asentamientos de las zonas áridas y semiáridas, con recursos limitados de agua y suelo. El aprovechamiento del agua del Río Mendoza ha permitido la conformación del oasis. Las 
características de su suelo y clima son propicias para el desarrollo agrícola y elaboración de vinos de calidad. El paisaje y los elementos patrimoniales que lo integran sumado a la calidad del vino producida en sus tierras es reconocido nacional e internacionalmente en los mercados económicos, turísticos y culturales. De ellos nos focalizamos para el presente estudio en los departamentos de Maipú y Luján de Cuyo ya que son los centros de atracción enoturística y aún poseen en su territorio mayor superficie agro - vitivinícola. Desde fines del siglo $X X$ se ha conformado una estrecha relación como estrategia de mercado entre el turismo cultural y enológico, la recreación y la producción vitivinícola. Esto condujo a que las bodegas transformaran sus instalaciones en función de poder brindar servicios mixtos entre ellos degustaciones, recorridos por viñedos, restaurantes, exposiciones de arte, experiencias interpretativas en las etapas de elaboración, alojamiento como una propuesta de actividades complementarias a la venta del producto. No obstante, en el informe del Instituto Nacional de Vitivinicultura INV del período 2000 - 2010 - 2018 sobre la evolución de la superficie de vid en Mendoza nos presenta que el único departamento que aumentó la superficie vitivinícola con un crecimiento del $57,5 \%$ en el total de su superficie desde el año 2000 fue Luján de Cuyo, mientras que Maipú decreció un $7 \%$ en el mismo período.

Esta información se confrontó con lo observado en el trabajo de campo realizado sobre el paisaje agrícola vitivinícola del AMM y en el análisis diacrónico de las fotos satelitales de Google earth $(1984,1990,1995,2001,2010,2015,2020)$ que en la secuencia de las fotos satelitales se observa el avance urbano sobre lo rural. De acuerdo al diagnóstico patrimonial del paisaje (Manzini, 2017) uno de los factores que han influido en la degradación del carácter en el paisaje agrícola vitivinícola observado en estos departamentos ha sido ocasionado por la pérdida de las superficies cultivadas ante un nuevo uso del suelo como el habitacional en zona de interface y rural. Esto se debe tanto al avance urbano de los centros distritales y departamentales acontecido en el tiempo, como por la introducción de barrios privados en zonas de cultivo. Esto se puede observar en el paisaje de los distritos rurales de Russell, Cruz de piedra y Lunlunta, del departamento de Maipú y en los distritos de Mayor Drummond, Carrodilla y Vistalba del departamento de Luján. A ello se le suma, el deterioro y desaparición de bienes patrimoniales vinculados a la industria vitivinícola, ya sea, por el deterioro edilicio como por abandono de sus funciones originales tanto de las bodegas como de viviendas con valor patrimonial.

El agravante de esta situación como se mencionó en el Plan del ordenamiento territorial de Mendoza de la Secretaría de Ambiente y Ordenamiento Territorial, Agencia Provincial de Ordenamiento Territorial, Gobierno de Mendoza (PPOT, 2017) es que la urbanización amenaza con ocupar zonas con suelos fértiles de alto valor ecológico y buenas condiciones ambientales para el cultivo de vides, frutales y hortalizas. A ello se le suma que estas tierras son escasas en el territorio de la provincia, con dificultad para la extensión de las áreas irrigadas debido al déficit hídrico existente y al costo económico que implica. Esta particularidad denunciada por la prensaiii se ve agravada en el presente por las sostenidas crisis económicas acontecidas y la falta de rentabilidad del agro para pequeños productores, incentivando a que las propiedades rurales dejen de tener un uso del suelo agrícola. A ello se le suma, la continua intervención en la red caminera que permite un desplazamiento rápido desde los barrios en zonas rurales hacia los núcleos urbanos, más los 
cambios en el ideal de la forma del habitar de las clases medias y altas de la sociedad demandantes de un estilo de vida de mejor calidad ambiental y en busca de protección ante los problemas de seguridad agravados por la problemática social. En consecuencia, el paisaje en estudio continúa con el transcurso del tiempo perdiendo su carácter distintivo e identitario y el potencial turístico que posee. Esta problemática acontece en especial en las zonas de interface, que son los territorios expuestos a mayor tensión de intereses y con mayor cercanía a las urbes. No obstante, es importante destacar que la forma material del paisaje es producto de procesos culturales - sistemas concretos de transformación de la organización territorial acontecidos en el tiempo. Según Navarro Bello (2004) la concepción del tema como un sistema integrado permite el análisis y comprensión de pautas y estructuras que materializan en el paisaje el ideario de cada etapa cultural.

La manifestación formal de su identidad en el territorio, es decir, el carácter del paisaje, como sostienen los autores Mata Olmos (2008); Cruz Pérez y Español Echaniz (2009) es un valor diacrónico que incorpora tanto la organización actual que tiene el paisaje como todas aquellas que ha tenido, pues ellas constituyen un valor trascendente de su identidad. Martínez de Pisón (2007) sostiene que en los paisajes rurales las formas se conforman por un proceso acumulador histórico, sobre el potencial ecológico, de manera que fijan funcionalmente el legado del pasado. Apareciendo según Mata Olmos (2008) ante el observador como un magno documento territorial para ser leído e interpretado como representante de la memoria de cada lugar y de la herencia transmitida a lo largo del tiempo, donde el espacio y los elementos que le dan forma permiten contemplar nuestra historia.

El enfoque diacrónico sumado a la complejidad del contenido histórico del paisaje es lo que entendemos como su dimensión histórica y está estrechamente ligada a los valores estéticos que expresan el sentido de cada lugar. El estudio histórico del paisaje nos permite por un lado visualizar y comprender su proceso evolutivo como también detectar los elementos patrimoniales que componen el paisaje (edificios, sitios, áreas de valor histórico y ejes) como hitos - huellas antrópicas distribuidas en el territorio integradas a los aspectos físico - naturales, y que han sido partícipe en la conformación del territorio sobreviviendo a los cambios acontecidos como testimonio de las diversas épocas integrándose todas ellas en el paisaje que se observa en el presente. Así mismo, si bien el paisaje integra como un todo estas capas temporales e hitos, existen sectores del territorio que tienen mayor predominancia de características históricas y elementos patrimoniales de una época determinada en relación a otras, lo que permite analizar y catalogar el paisaje en Unidades visuales de Paisaje de valor patrimonial.

Muñoz Pedreros (2017) sostiene que al paisaje se lo puede considerar como la expresión espacial y visual del medio, no obstante, al transitar por el territorio se observa que la complejidad del contenido semántico histórico e identitario, junto a sus elementos patrimoniales integrados a los aspectos físico - naturales del paisaje, no siempre se perciben claramente. Es decir, sus características físicas junto a las históricas patrimoniales no pueden ser observables desde cualquier punto del paisaje ni poseen la misma calidad visual. Se entiende por calidad visual según Montoya Ayala y otros (2003) al conjunto de características visuales y emocionales que califican la belleza del paisaje y en nuestro estudio entendemos por calidad visual patrimonial como al grado de excelencia de los atributos visuales de las características físicas e históricas del paisaje. En 
este marco sostenemos como hipótesis general que el reconocimiento de los valores visuales del paisaje en conjunción a la dimensión histórica permite ordenar de forma adecuada la implantación de determinados usos y actividades turísticas en el territorio. Este enfoque en el AMM no está lo suficientemente estudiado y aprovechado por los diversos actores vinculados al turismo y ordenamiento territorial. En consecuencia, nos proponemos como objetivo general del trabajo efectuar un análisis de la calidad visual patrimonial en relación a la dimensión histórica del paisaje agrícola del AMM con el fin de contribuir con un turismo sustentable que promueva un desarrollo local.

2 - ACERCA DE LA METODOLOGÍA PARA LA EVALUACIÓN DE LA CALIDAD VISUAL PATRIMONIAL DEL PAISAJE.

Para analizar la calidad visual patrimonial del paisaje se aplicó una metodología de investigación interdisciplinaria que integra la historia, la arquitectura y la geografía. Esto se debe a que la dimensión temporal - histórica sincrónica y diacrónica es fundamental para el entendimiento y aprecio del paisaje y sus elementos constitutivos, ya que pone de manifiesto tanto el significado cultural que nutre al valor patrimonial del paisaje, como la cualidad dinámica de los procesos que lo conforman y lo degradan. Por otra parte, la arquitectura nos brinda herramientas para el estudio de los bienes patrimoniales que se integran en el paisaje y la geografía nos permite analizar el paisaje desde sus aspectos físicos, naturales, antrópicos en relación al territorio y perceptuales. Partícipe de este marco metodológico integrado, para la presente investigación se aplicó la metodología elaborada, probada y validada en las investigaciones efectuadas por Cirvini y Manzini (2012) y Manzini (2017). Esta consiste, en efectuar un camino iterativo entre el conocimiento histórico contextual de la industria agro-vitivinícola y el territorio estudiado, lo que permite realizar una reformulación crítica de las hipótesis acerca de lo que podemos hallar en el territorio, y una vez en el territorio este conocimiento nos reafirma y alerta sobre nuevos indicios, signos y marcas ubicadas en el paisaje correspondiente a diferentes tiempos. Es decir, en un camino de doble circulación, vamos al territorio y a su vez, buscamos datar y explicar elementos significativos del paisaje actual para hacer posible su lectura contextual, ya que el saber histórico opera como una herramienta indispensable de comprensión de las diversas capas que se superponen en lo que vemos hoy como un todo integrado. Una vez identificadas las características y elementos de valor histórico patrimonial se integra a este análisis las características físicas - naturales (bióticas y abióticas) y las perceptuales, que en su conjunto permiten definir las Unidades Visuales de Paisaje (UVP) como las áreas visuales homogéneas.

Las Unidades Visuales de Paisaje (UVP) para la presente investigación son consideradas fuentes documentales que para poder relevar la información se requiere detectar e identificar en el territorio puntos de observación (PO); líneas de observación (LO) y los recorridos escénicos paisajísticos patrimoniales (REP) desde donde se puede efectuar la observación de los valores visuales patrimoniales del paisaje en estudio en relación a la historia. Para ello se realizó una preselección en las fotos satelitales de los posibles (PO); (LO) y (REP) en vinculación con el conocimiento histórico del territorio y los elementos patrimoniales (Edificio, Sitio, EJES, y Áreas de valor Histórico AVH) que se integran en el paisaje agrícola de los departamentos de Luján de Cuyo y 
Maipú del AMM. Cuando se confrontó en el trabajo de campo efectuado en el territorio la preselección efectuada de los (PO), (LO) y (REP) fue necesario ajustar, como se tenía previsto, el criterio de selección de los mismos para poder detectar los de mayor significancia en la calidad de sus vistas y que permitan realizar la observación y registro de datos, a saber:

A-Puntos de Observación (PO): Los Puntos de Observación son los lugares del territorio desde donde se percibe el paisaje. Para su selección no es suficiente el tipo de vista ya sea focalizada de 0 a $200 \mathrm{mts}$ de visibilidad, intermedia o cerrada de 200 a $800 \mathrm{mts}$ y panorámica de 800 a $2600 \mathrm{mts}$, ante ello es necesario tener en cuenta las características en torno al tipo de accesibilidad, y posibilidad de permanencia requeridas para poder contemplar el paisaje desde sus mejores vistas y realizar las mediciones de los ángulos de visibilidad, registrar las referencias visuales en las vistas, los límites visuales y objetivar de esta manera lo que se ve. La accesibilidad a un PO depende si se encuentra en espacio o bien público o privado. El espacio de uso público permite un acceso libre como en (plazas, parques, miradores, monumentos, veredas, puentes, rotondas con accesibilidad, calles, y patrimonio privado pero de uso público como explanadas de iglesias y estaciones de ferrocarril). En cambio los espacios y bienes privados (Bodegas, fincas, bienes patrimoniales de propiedad privada), tienen el acceso condicionado. Otra característica a considerar es el modo de accesibilidad al PO si es (vehicular, ciclística y peatonal). Estas características son fundamentales para el diseño de recorridos escénicos paisajísticos patrimoniales (REP) y las Rutas culturales de las Unidades Visuales Patrimoniales. También influye en el tipo de uso o actividad que se puede realizar en los PO como (académicas, científicas, recreativas y de gestión). De la posibilidad de permanencia se define si es un punto de observación estático (es posible la permanencia en el lugar) o dinámico (no es posible la permanencia en el lugar, pero es identificable mientras se está efectuando el desplazamiento). Destacamos que los PO pueden integrar o no líneas de observación LO.

B- Líneas de Observación (LO): Las Líneas de Observación son las vías de comunicación tanto principales como secundarias que permiten percibir el paisaje en movimiento. Para su selección se requirió tener en cuenta el tipo de vía (Ruta, calle, huella, ciclovía), estado de la vía (bueno, regular, malo) y los PO existentes (Estáticos o dinámicos) en la vía de circulación, los elementos patrimoniales del paisaje observables en su recorrido (Edificios, Sitios, Ejes, Área de Valor Histórico $\mathrm{AVH}$ ), los elementos de referencia naturales del paisaje (bióticos y abióticos) en las diferentes estaciones y momentos del día. Como también se tuvo en cuenta las zonas de mayor degradación del paisaje. En su relevamiento se requiere identificar y georreferenciar un punto de inicio y fin de la Línea de observación, las características observables y su localización para un reconocimiento en el recorrido, lo que requiere identificar de una forma precisa y cuantificable los elementos de referencia en el paisaje. Para ello se requiere definir un PO estático y allí efectuar la toma del ángulo vertical y horizontal para su registro e identificación del elemento en la vista que se observa en el PO.

C-Recorridos escénicos paisajísticos Patrimoniales (REP): Los Recorridos Escénicos Paisajísticos Patrimoniales, son las vías de comunicación o caminos que tienen un valor paisajístico excepcional por atravesar y tener vistas sobre el paisaje que permitan observar el valor natural, 
histórico y patrimonial y pueden integrar puntos de observación como líneas de observación. En su relevamiento se requiere identificar y georreferenciar un punto de inicio y finalización, como también es necesario la identificación de los PO y LO que los integran y su secuencia en el recorrido. A ello se le suma que se requiere el relevamiento de las características observables y su localización para un reconocimiento en el recorrido, lo que es necesario identificar de una forma precisa y cuantificable los elementos de referencia en el paisaje. Para ello se requiere definir un PO estático y allí efectuar la toma del ángulo vertical y horizontal para su registro e identificación del elemento en la vista que se observa en el PO.

Los PO, LO y REP nos brindan tres tipos de observación del paisaje (estática, dinámica y mixta) a lo que se suma la posibilidad de una vista focalizada, intermedia o panorámica, funcionando en conjunto o red como una herramienta de lectura de la dimensión histórica del paisaje patrimonial. Esto es posible ya que al efectuar el recorrido de una forma guiada por el territorio ante la observación de las vistas excepcionales seleccionadas y sus elementos patrimoniales se produce la trasmisión del contenido semántico histórico del paisaje en estudio. De acuerdo a como se transite estos caminos (caminado, a caballo, bicicleta, vehículos a motor) se podrá acceder a mayor detalle de percepción, no sólo para la vista, sino también para otros sentidos como el oído, el olfato o incluso el tacto. Información que enriquece el diseño de recorridos y rutas. Además el conjunto de esta información es necesaria y de utilidad para el diseño del Mapas de Identificación y Gestión de las Unidades Visuales Patrimoniales y sus elementos constitutivos del paisaje.

Destacamos que los puntos de observación en nuestro marco geográfico conforman una red integrada de 90 localizaciones georeferenciadas. Al departamento de Maipú corresponden 55 PO y 30 a Luján de Cuyo. A ello se le suma que para obtener mejores vistas y puntos donde observar el problema se definieron puntos de observación en el departamento de Capital $1 \mathrm{PO}$, en el departamento de Las Heras 4 PO.

\subsection{Acerca de la metodología para el análisis de los resultados e interpretación de los datos.}

Para el presente trabajo se presentan los datos obtenidos de la información relevada desde los puntos de observación PO estáticos. Desde su ubicación georeferenciada se puede efectuar una observación directa y registro de los elementos y características del paisaje. Las características cualitativas que se observan son cuantificadas y ponderadas en torno a tres rangos de valor ALTO, MEDIO y BAJO. Estos datos son de utilidad en el diseño de estrategias que permiten ordenar de forma adecuada la implantación de usos y actividades turísticas en un territorio. A mayor cantidad de puntos de observación desde los que se pueda detectar las características y sumado al rango de valor correspondiente, significa mayor influencia o presencia en el territorio de la variable estudiada.

Para poder relevar con precisión científica los ángulos de visibilidad, los límites visuales de las Unidades Visuales Patrimoniales (UVP) y tomar el registro de las referencias visuales en las vistas de los PO, LO y REP, y objetivar de esta manera lo que se ve, se creó una herramienta científica Eco-amigable de precisión que mide magnitudes angulares verticales y horizontales en alta resolución en el Sector experimental del Grupo Historia y Conservación Patrimonial del 
INCIHUSA-CONICET en el 2019 por el Ing. José Gómez Voltán, la que fue denominada TEÁNGULO.iv

Figura 1. Mosaico de fotos instructivas de la herramienta y ejemplos de lecturas de los puntos horizontales y verticales
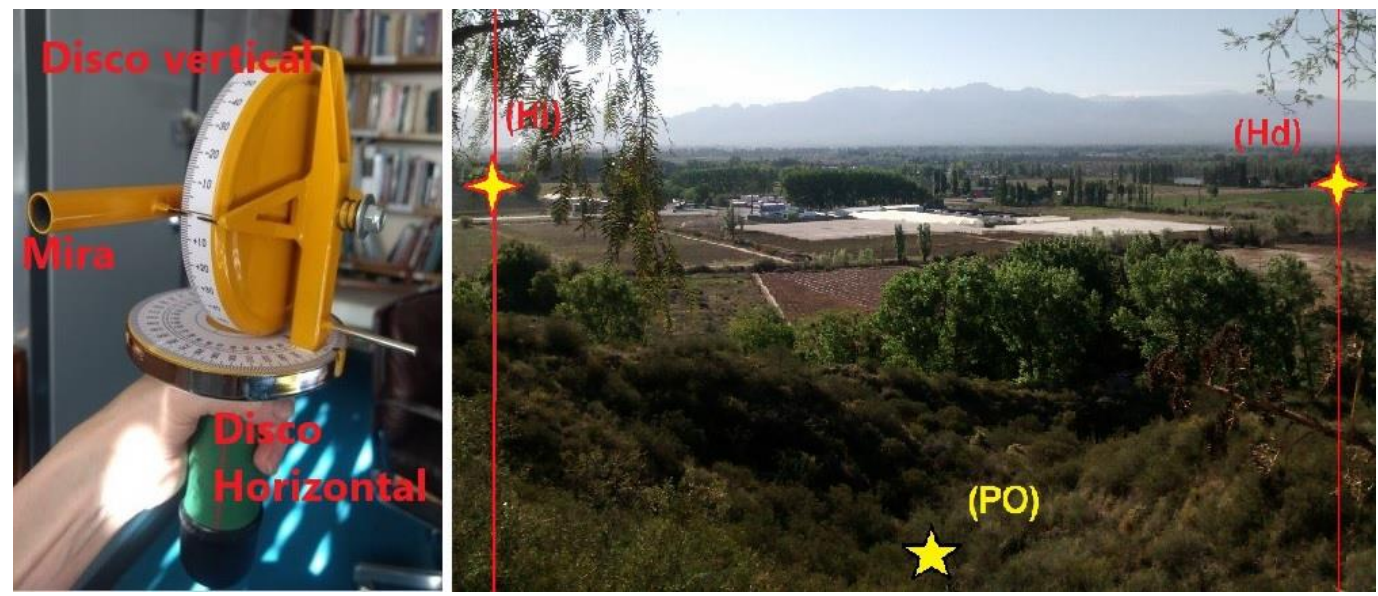

Fuente: Archivo personal del autor - INCIHUSA - CONICET, fotos tomadas en el 2019.

\section{3 - ACERCA DE LA DETERMINACIÓN DE LAS UNIDADES VISUALES PATRIMONIALES (UVP) \\ DEL PAISAJE AGRÍCOLA - VITIVINÍCOLA DE LUJÁN DE CUYO Y MAIPÚ}

Las Unidades Visuales Patrimoniales de Paisaje (UVP) se caracterizan por una estructura interna que las dota de sentido y coherencia. En ellas se observa los elementos constitutivos del paisaje y un criterio dominante en su caracterización que le otorga la homogeneidad que las diferencia de otros paisajes. Esta homogeneidad varía según la escala de observación. En el Área metropolitana de Mendoza el criterio dominante de homogeneidad en la unidad de paisaje de oasis es en base al sistema agrícola. Por lo que desde este criterio nuestro marco geográfico de estudio corresponde y se integra en el paisaje del Oasis Norte de Mendoza. Pero cuando nos acercamos en escala de observación a las áreas que lo integran se observan paisajes urbanos, industriales, paisajes correspondiente a reservas naturales, del secano y rurales - agrícolas irrigados. Cada uno de ellos poseen sus especificidades sus sistemas internos estrechamente relacionados a su entorno y entre ellos, que le otorga sus características distintivas poseedoras de valor patrimonial.

Para efectuar el análisis de las características distintivas del paisaje patrimonial del Área Metropolitana de Mendoza hemos identificado y seleccionado en el territorio zonas homogéneas las basándonos en un criterio histórico patrimonial que tienen un grado visual de excepcionalidad. En ellas, la dimensión histórica y los elementos históricos patrimoniales constitutivos del paisaje de diferentes tiempos, sumado a las características principalmente de los usos del suelo y las características naturales morfológicas del paisaje le otorgaron el sentido de coherencia a las unidades visuales de paisaje de valor patrimonial. Pero al realizar el trabajo de campo observamos desde los puntos de observación y líneas de observación que las (UVP) por la escala del marco geográfico de estudio correspondiente al paisaje agrícola de los departamento de Luján de Cuyo y Maipú para apreciar su valor histórico patrimonial requiere de recorridos que concatenen una 
sucesión de vistas excepcionales que las conforman. Del análisis de lo observado en el territorio de los departamentos de Luján de Cuyo y Maipú se definieron las siguientes (UVP) v:

Tabla 1

Unidades Visuales Patrimoniales del Paisaje Agrícola (UVP)

\begin{tabular}{|c|c|c|c|}
\hline $\mathbf{N}^{\circ}$ UVP & Nombre & $\begin{array}{c}\text { Departamento } \\
\text { s }\end{array}$ & Ubicación \\
\hline UVP1 & $\begin{array}{l}\text { UNIDAD VISUAL } \\
\text { PATRIMONIAL DEL } \\
\text { PAISAJE DEL } \\
\text { METROPOLIZACIÓN }\end{array}$ & $\begin{array}{l}\text { Luján de Cuyo } \\
\text { y Maipú }\end{array}$ & $\begin{array}{l}\text { Tierras Agrícolas vitivinícolas de Luján } \\
\text { de Cuyo y Maipú al Norte del Río } \\
\text { Mendoza - de Luján: Chacras de Coria, } \\
\text { Vistalba, Carrodilla, Mayor Drummond. } \\
\text { De Maipú: Ciudad de Maipú, Coquimbito; } \\
\text { Russell, Cruz de Piedra y Lunlunta }\end{array}$ \\
\hline UVP2 & $\begin{array}{lr}\text { UNIDAD } & \text { VISUAL } \\
\text { PATRIMONIAL DE LOS } \\
\text { PAISAJES DE LA } \\
\text { INDUSTRIALIZACIÓN Y } \\
\text { EXPANSIÓN } \\
\text { VITIVINÍCOLA: PAISAJE } \\
\text { DE LA 1RA MOD. } \\
\text { AGRÍCOLA VITIVINÍCOLA } \\
\text { DE MAIPU AL SUR RUTA } \\
7\end{array}$ & Maipú & $\begin{array}{l}\text { Tierras agrícolas vitivinícolas de Rodeo } \\
\text { del Medio, General Ortega y Fray Luis } \\
\text { Beltrán de la Ruta Nac. } 7 \text { al Sur }\end{array}$ \\
\hline UVP3 & $\begin{array}{lr}\text { UNIDAD } & \text { VISUAL } \\
\text { PATRIMONIAL DE LOS } \\
\text { PAISAJES DE LA } \\
\text { INDUSTRIALIZACIÓN Y } \\
\text { EXPANSIÓN } \\
\text { VITIVINÍCOLA: PAISAJE } \\
\text { DE LA } \quad \text { IRA MOD. } \\
\text { AGRÍCOLA VITIVINÍCOLA } \\
\text { DE MAIPU AL NORTE } \\
\text { RUTA } 7\end{array}$ & Maipú & $\begin{array}{l}\text { Tierras agrícolas vitivinícolas de Rodeo } \\
\text { del Medio y Fray Luis Beltrán de la Ruta } \\
7 \text { al norte }\end{array}$ \\
\hline UVP4 & $\begin{array}{lr}\text { UNIDAD } & \text { VISUAL } \\
\text { PATRIMONIAL DE LOS } \\
\text { PAISAJES DE LA } \\
\text { INDUSTRIALIZACIÓN Y } \\
\text { EXPANSIÓN } \\
\text { VITIVINÍCOLA: PAISAJE }\end{array}$ & Maipú & Distrito de San Roque de Maipú \\
\hline
\end{tabular}


DE FINCAS Y CHACRAS

DE SAN ROQUE

UVP5

UNIDAD

VISUAL Maipú

Distrito Barrancas de Maipú

PATRIMONIAL DE LOS

PAISAJES DE LA

INDUSTRIALIZACIÓN Y

EXPANSIÓN

VITIVINÍCOLA: PAISAJE

AGRO VITIVINÍCOLA DE

BARRANCAS

UVP6

UNIDAD

VISUAL Luján de Cuyo

Luján vitivinícola al Sur del Río Mendoza

PATRIMONIAL

$D E L$

Distrito de Perdriel

PAISAJE VITIVINÍCOLA

DE TRANSICIÓN DE LA

INDUSTRIALIZACIÓN A

LA 2DA

MODERNIZACIÓN DE

PERDRIEL

UVP7

UNIDAD

VISUAL Luján de Cuyo

Distrito de Agrelo e Industrial de Luján de

PATRIMONIAL DEL Cuyo

PAISAJE DE LA 2da

MOD. VITIVINÍCOLA DE

LA ZONA INDUSTRIAL

UVP8

UNIDAD

VISUAL Luján de Cuyo

Distrito de Ugarteche de Luján de Cuyo

PATRIMONIAL DEL

PAISAJE DE LA 2da

MOD. VITIVINÍCOLA DE

UGARTECHE

UVP9

$U N I D A D$

VISUAL Luján de Cuyo

Distrito de Carrizal Luján de Cuyo

PATRIMONIAL DE LOS

PAISAJES DE LA

INDUSTRIALIZACIÓN Y

EXPANSIÓN

VITIVINÍCOLA: PAISAJE

AGRO VITIVINÍCOLA DE

CARRIZAL

UVP11 UNIDAD VISUAL Luján de Cuyo Distrito de Ugarteche 7 Carrizal de Luján PATRIMONIAL DEL de Cuyo. 


\section{PAISAJE NATIVO \\ SEMIDESÉRTICO DE \\ LAS TRAVESÍAS \\ CUYANAS.}

Fuente: Elaboración propia del autor

Se observa en los recorridos de las Unidades Visuales Patrimoniales del Paisaje que hay zonas de mayor concentración de bienes como edificios, sitios y ejes de valor patrimonial que otras. Los elementos que constituyen el paisaje agrícola vitivinícola de Luján de Cuyo y Maipú que integran (Edificios, Sitios, Ejes, Áreas y AVH Áreas de valor histórico) son poseedores de valor histórico patrimonial, verdaderos hitos en el paisaje referentes en el territorio y de nuestra identidad. Los mismos son los componentes significativos del paisaje y requieren de una apropiada conservación en sus diversas etapas de gestión y con un enfoque integrador de conjunto sistémico.

Figura 2. Mosaico de fotos de elementos que constituyen el paisaje cultural del Área Metropolitana de Mendoza, ejemplos de EJES, Edificios y Sitios. 


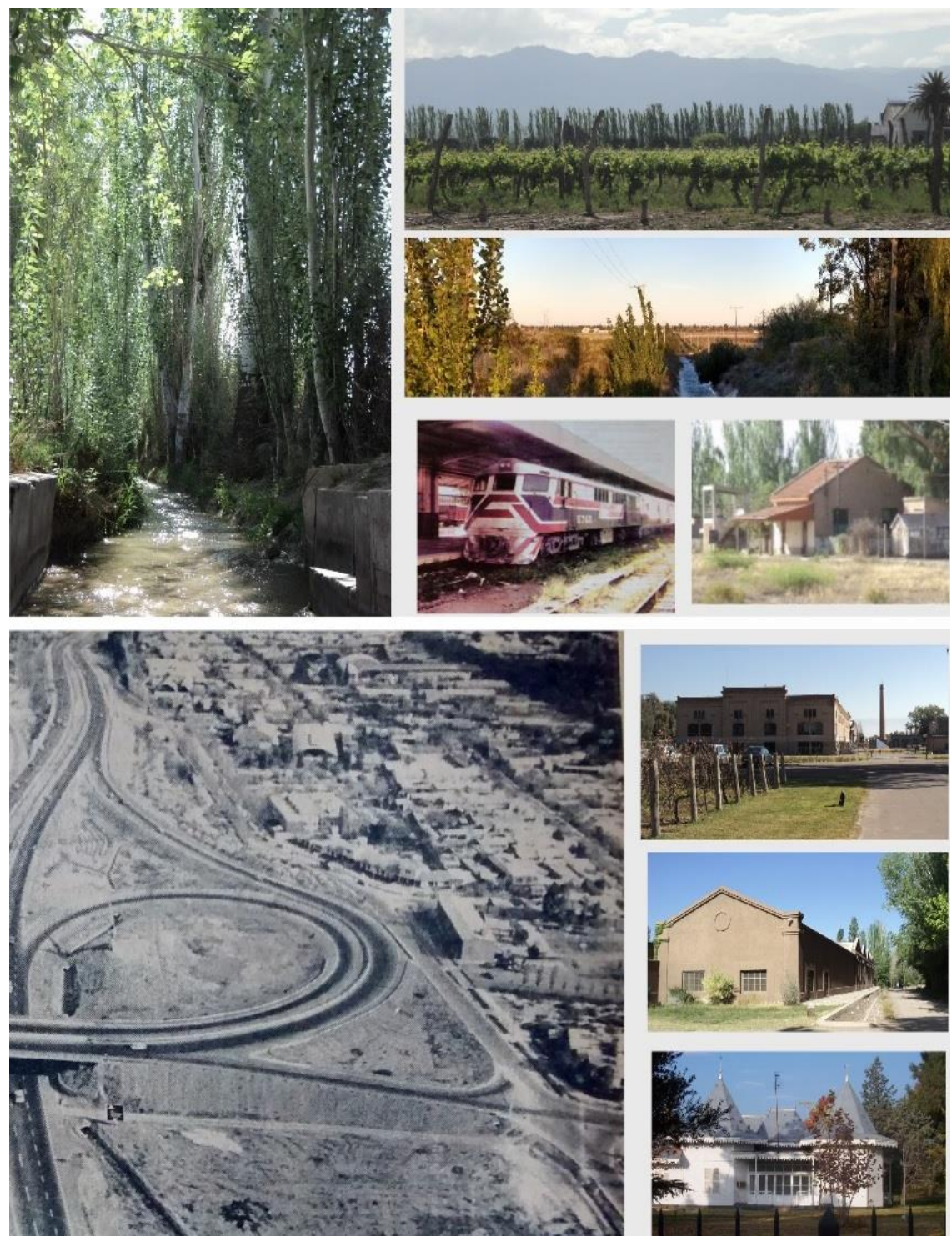

Fuente: Archivo personal del autor - INCIHUSA - CONICET.

Del análisis histórico de los cambios acontecidos en el tiempo del territorio de las unidades visuales patrimoniales del paisaje de los departamentos de Maipú y Luján de Cuyo, se observa que el departamento de Maipú de la Ruta 7 al sur que abarca la UVP2 Tierras agrícolas vitivinícolas de Rodeo del Medio, General Ortega y Fray Luis Beltrán posee mayor cantidad de elementos proto industriales (1850 - 1885) de valor patrimonial que el paisaje de Luján de Cuyo. La traza de caminos que fueron estructurando el territorio departamental que se observa en la actualidad se fue consolidando sobre caminos del siglo XIX, como el antiguo camino de las postas actual carril nacional. Posteriormente, el avance de la industrialización fue transformando las características pretéritas incorporando nuevos tipos de bienes con características materiales de la 1ra modernización (1885 - 1930) ya sea en la arquitectura industrial como en la habitacional y en el territorio con la introducción del ferrocarril y sistema modernos de riego desdibujando el paisaje proto - industrial de los que quedan escasos referentes como el Museo Casa de las Bóvedas en Gral. Ortega y la antigua casa de Juan de la Cruz Videla en Cruz de Piedra. Avanzando sobre el siglo XX en la etapa de la expansión vitivinícola de 1930 hasta 1990 que abarca la UVP4 Fincas y chacras de 
San Roque los antiguos caminos se extendieron apropiándose de nuevas tierras para uso agrícola, cambiando las características materiales de las edificaciones productivas y habitacionales de la industrialización. En cambio, en los departamento de Luján de Cuyo si bien hubieron sectores productivos y habitacionales en el siglo XIX quedan pocas edificaciones que lo atestigüen como la Toma de los Españoles y el antiguo zanjón Cacique Guaymallén.

En consecuencia, desde los PO se detecta que al Norte del Río Mendoza las características del paisaje vitivinícola son de la industrialización (1885 - 1930), expansión vitivinícola (1930 - 1990) y de la metropolización (desde 1990 hasta la actualidad), estas tierras corresponden a la UVP1: la que hemos denominado Paisaje agro vitivinícola de la Metropolización ya que la mixtura de características temporales han desdibujado su carácter pretérito de las tierras Agrícolas vitivinícolas de Chacras de Coria, Vistalba, Carrodilla, Mayor Drummond, lo que también abarca del departamento de Maipú la Ciudad, Coquimbito; Russell, Cruz de Piedra y Lunlunta. En cambio, en Luján de Cuyo al sur del río Mendoza se observa la UVP6: el distrito de Perdriel con características de la 1 ra modernización (1885 - 1990) y 2da modernización (desde 1990 hasta la actualidad) al que se denominó de transición que da lugar hacia el sur la UVP7 en Distrito de Agrelo e Industrial y UVP 8 del distrito de Ugarteche, ambos correspondientes a la 2da modernización vitivinícola (desde 1990 hasta la actualidad) cuyas tierras fueron trabajadas y consolidadas desde mediados del siglo XX hasta la actualidad. En ellas es donde se ubican los 14 PO que detectan esta característica de nuevas construcciones como Bodega Séptima y las características de sus viñedos de la 2da modernización.

Los bienes patrimoniales le otorgan significado histórico al paisaje, estos permiten efectuar lectura del sentido histórico. En Maipú se detecta que el valor histórico de los elementos patrimoniales del paisaje es alto ya que de la información que brindan los $\mathrm{PO}$ (41 corresponde a ALTO, 13 a MEDIO, 1 BAJO). Además se observa una buena autenticidad del valor histórico del paisaje de los PO (39 detectan ALTO, 12 MEDIO, 4 BAJO). En el caso de Luján también tiene un valor histórico alto ya que de los PO relevados 26 dan ALTO, 1 MEDIO y $3 \mathrm{BAJO}$, al igual que la autenticidad del valor histórico del paisaje que es alta ya que 23 PO dan ALTO, 4 MEDIO y 3 BAJO. Entendiéndose por autenticidad al grado de veracidad que tiene el paisaje en sus características constitutivas de su valor histórico.

Figura 3. Vista del punto de observación PO 79 - Virgen de Lourdes Departamento de Luján de Cuyo. En el mismo se observa un ALTO valor histórico del paisaje rural integrado por la Gruta, los cultivos de viñedos y los ejes camineros y arboledas de valor patrimonial del departamento. 


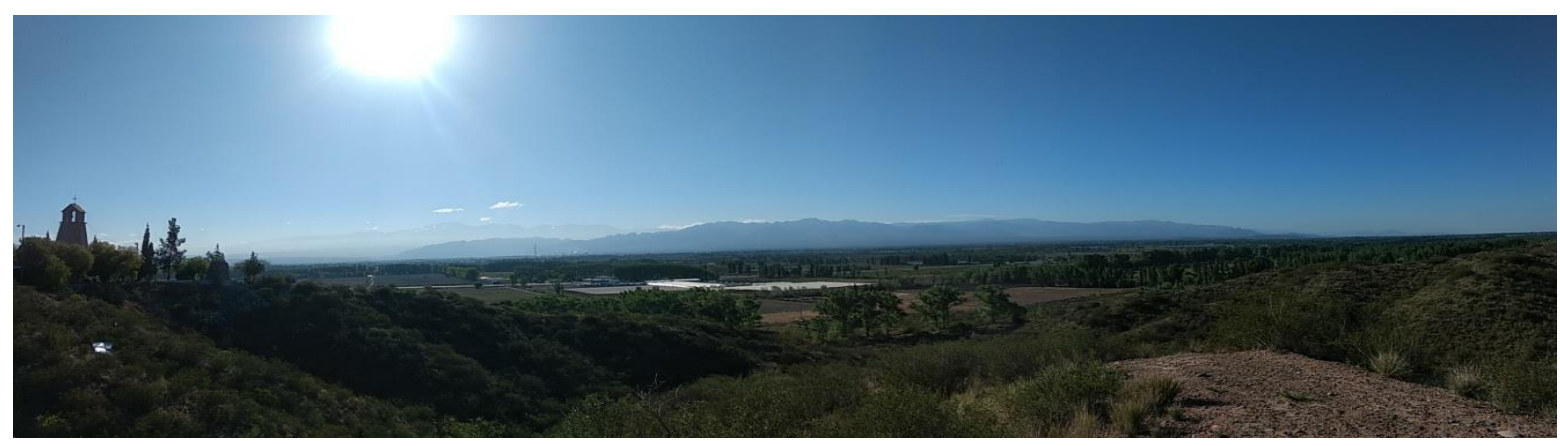

Fuente: Archivo personal del autor - INCIHUSA - CONICET, foto tomada en el 2017.

\section{4 - LOS USOS DEL SUELO DE LAS UNIDADES VISUALES DE PAISAJE COMO RECURSO VISUAL TURÍSTICO.}

Destacamos que los usos del suelo en el paisaje son una de las características de mayor influencia en el carácter del paisaje ya que las funciones que se desarrollan sobre la superficie del territorio indefectiblemente tienen su manifestación formal y material y de sus características son la resultante observable. El tipo de actividad cuando se manifiesta con características similares constituye una zona homogénea. Al identificar el tipo de zona estamos efectuando una lectura del paisaje que nos permite comprender cuales son las actividades principales que se están efectuando y sus condicionantes en la dinámica del paisaje y el tipo de elementos estructurante que los constituyen.

Para evaluarlo en relación a la dimensión patrimonial nos interesa saber si el uso que se hace del suelo posee características homogéneas y si son únicas que se diferencian del resto del paisaje lo que denominamos rareza. La homogeneidad es el conjunto de cualidades del paisaje formado por elementos semejantes. La HOMOGENEIDAD Y RAREZA le otorga valor al paisaje desde la mirada patrimonial y contribuyen a la definición de las Unidades Visuales del paisaje. En este marco, se analizó: Uso del suelo predominante; Uso del suelo secundario; Homogeneidad del uso del suelo observado (ALTO MEDIO BAJO); Rareza del uso del suelo (ALTO MEDIO BAJO); Tipo de zona (URBANO, URBANO DISTRITAL, INTERFASE, RURAL)

De acuerdo al relevamiento efectuado en el trabajo de campo desde 55 Puntos de observación PO en el departamento de Maipú se observa que el Uso del suelo predominante es el Agrícola y según se observó en $47 \mathrm{PO}$ y el uso del suelo secundario corresponde al Habitacional como se detectó desde 37 PO. La Homogeneidad del uso del suelo en 36 PO es ALTA, en 11 PO BAJA y en 8 PO MEDIA. En cambio la Rareza del uso del suelo es ALTA observada en los 55 PO. En el Departamento de Luján de Cuyo la cantidad total de PO analizados es de 30. EL Uso del suelo predominante y el secundario es el Agrícola visto desde 12 PO. La Homogeneidad del uso del suelo predominante observada desde 15 PO es ALTA, BAJA vista desde 10 PO y MEDIO 5 PO. La Rareza del uso del suelo predominante es ALTA vista desde 25 PO, MEDIA desde 3 PO y BAJA desde 2 PO. 
De la observación y análisis de estos datos se plantea que tanto para Maipú como para Luján de Cuyo la rareza del paisaje predominante es alta. Esto se debe a que en una provincia de características de zonas áridas y semi áridas, con recursos limitados de agua y suelo cultivable, los oasis son paisajes excepcionales. Por lo tanto, si efectuamos el análisis desde un marco provincial y regional las unidades de paisajes definidas en base a un sistema agrícola son de una Alta rareza. Así mismo, en este marco en el departamento de Luján de Cuyo se observó dos puntos de observación con rareza Baja, estos son ubicados en el departamento de Ugarteche en cuyo límite de zona agrícola colinda con terrenos de flora y fauna nativa lo que en nuestro estudio se transformó en (LJ) UVP11: PAISAJE NATIVO SEMIDESÉRTICO DE LAS TRAVESÍAS CUYANAS. En este marco, dentro de los limites internos del oasis, la homogeneidad del uso del suelo en los departamentos de Luján de Cuyo y Maipú presenta variaciones ya que en el territorio en estudio se comparte distintos usos del suelo, como se puede observar en las zonas rural, de interface y urbana, que imprimen su característica en el paisaje generando variaciones que son las que contribuyeron junto a los otros factores históricos morfológicos y perceptivos a la definición de las Unidades visuales de paisaje dentro del Oasis Norte de Mendoza en el Área Metropolitana de Mendoza. En Maipú el tipo de zona visible desde los PO predominante fue la RURAL observable desde $39 \mathrm{PO}$, luego la interface observada desde 15 PO y finalmente la URBANO DISTRITAL desde 1 PO. En Luján al igual que en Maipú el tipo de Zona predominante es el RURAL observado desde 22 PO, INTERFACE desde 6 PO y urbano distrital desde $2 \mathrm{PO}$.

Figura 4. Vista del punto de observación PO - 81 Ruta 86 y Cobos Distrito de Ugarteche Departamento Luján de Cuyo. En el mismo se observa un ALTO valor de Homogeneidad del uso del

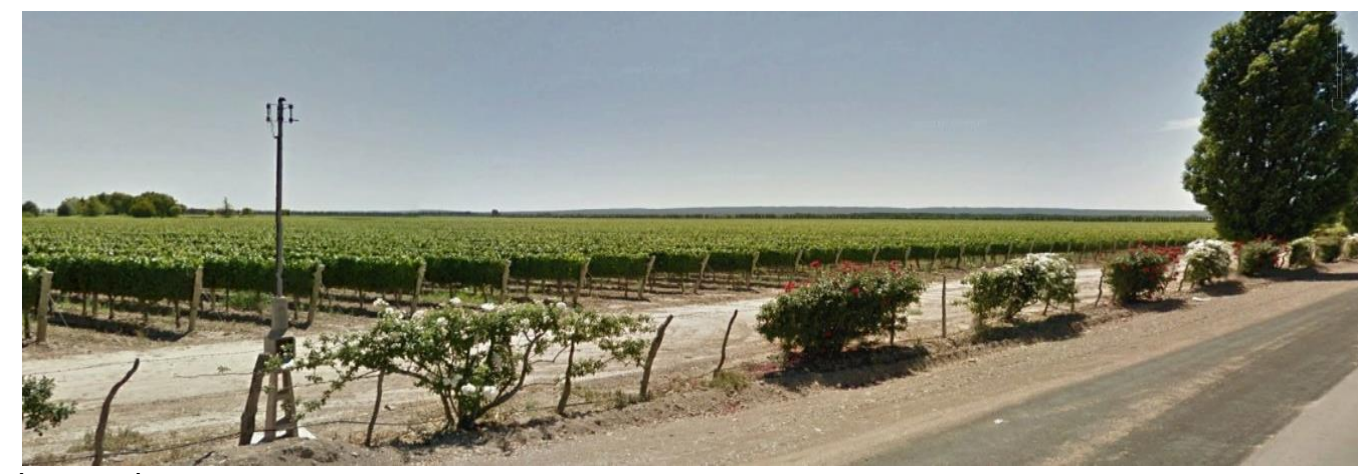

suelo observado.

Fuente: Archivo personal del autor - INCIHUSA - CONICET, foto tomada en el 2017.

Las variantes más significativas que le otorgan diferencias en el carácter de las UVP vinculado al uso del suelo son las siguientes:

\section{1 - Los usos del suelo y el carácter a escala de Unidad Visual de Paisaje:}

(LJ-MP) UVP1: PAISAJE DE LA METROPOLIZACIÓN (Tierras Agrícolas vitivinícolas de Luján de Cuyo y Maipú al Norte del Río Mendoza - de Luján: Chacras de Coria, Vistalba, Carrodilla, Mayor Drummond. De Maipú: Ciudad de Maipú, Coquimbito; Russell, Cruz de Piedra y Lunlunta). La cantidad total de PO analizados en la UVP son 8. Del análisis de los mismos el paisaje de esta UVP se caracteriza por ser agrícola, si bien aun en la actualidad se observa en zonas un uso del suelo 
predominante vitivinícola, olivícola que corresponde al uso observado en $7 \mathrm{PO}$; el uso del suelo secundario que es el habitar extraterritorial de barrio privado visto desde 4 (PO) está modificando o haciendo desaparecer el carácter agrícola dando como resultado que la Homogeneidad del uso predominante del suelo sea bajo detectado desde los 5 PO; constituyendo de esta forma un tipo de zona predominante de interfase.

(MP) UVP2: PAISAJE DE LA 1RA MOD. AGRÍCOLA VITIVINÍCOLA DE MAIPU AL SUR RUTA 7 (Tierras agrícolas vitivinícolas de Rodeo del Medio, General Ortega y Fray Luis Beltrán de la Ruta Mac. 7 al Sur). La cantidad total de PO analizados en la UP son 19. De ellos se observa que el uso del suelo predominante es tanto mixto (hortícola, vitivinícola) que corresponde a 8 (PO); en complemento el uso del suelo secundario es el habitar rural observado en 16 (PO); la Homogeneidad del uso predominante del suelo es alto de $15 \mathrm{PO}$. Como resultante el tipo de zona predominante es la rural en los 19 (PO).

(MP) UVP4: PAISAJE DE FINCAS Y CHACRAS DE SAN ROQUE. (Tierras Agrícolas vitivinícolas de San Roque). La cantidad total de PO analizados en la UVP son 1 de su lectura se percibe que el uso del suelo predominante es mixto agrícola de cultivo de hortalizas, viñas, olivos y flores; y el uso del suelo secundario es el habitar rural; la Homogeneidad del uso predominante del suelo es alto; como resultante el tipo de zona predominante es la rural.

(LJ) UVP6: PAISAJE VITIVINÍCOLA DE PERDRIEL. TIERRAS DE TRANSICIÓN DE LA INDUSTRIALIZACIÓN A LA 2DA MODERNIZACIÓN (Luján vitivinícola al Sur del Río Mendoza Distrito de Perdriel). La cantidad total de PO analizados en la UP son 4. En ellos se observa que el uso del suelo predominante es el agrícola vitivinícola observado en 3 (PO) y el secundario el habitacional distrital observado en 2 PO; la Homogeneidad del uso predominante del suelo es baja en 4PO; el resultado que se observa es el Tipo de zona predominante rural observada en 4 (PO).

(LJ) UVP7: PAISAJE DE LA 2da MOD. VITIVINÍCOLA DE LA ZONA INDUSTRIAL (Distrito de Agrelo e Industrial de Luján de Cuyo). La cantidad total de PO analizados en la UVP son 9. De ellos el uso del suelo predominante es el industrial agrícola vitivinícola en $9 \mathrm{PO}$; y el secundario es el industrial agrícola vitivinícola en 9 (PO); la Homogeneidad del uso predominante del suelo es Alta en 6 PO; como resultante el tipo de zona predominante es el rural y posee una zona urbana distrital.

(LJ) UVP8: PAISAJE DE LA 2da MOD. VITIVINÍCOLA DE UGARTECHE (Distrito de Ugarteche de Luján de Cuyo). La cantidad total de PO analizados en la UVP son 3 y el Uso del suelo predominante es agrícola vitivinícola observado en 2 PO; y el secundario es el industrial agrícola vitivinícola en 2 (PO); la Homogeneidad del uso predominante del suelo es alto en 2PO; dando como resultado un tipo de zona predominante rural con una zona urbana distrital.

En consecuencia, los usos del suelo son determinantes en la conformación del carácter y un recurso potencial para el turismo, lo que deja de manifiesto la necesidad de trabajar en una reglamentación de protección municipal de zonas en torno al uso del suelo para no perder la fortaleza del recurso turístico paisajístico como es el caso del distrito de Agrelo en Luján de Cuyo que el municipio lo declaró zona de reserva vitícola preservando así el paisaje del lugar, condicionando a los productores a mantener ese tipo de cultivo como prioridad. Como también promocionar recursos 
poco explotado el paisaje agrícola mixto que conjuga las plantaciones de hortalizas, con viñas, frutales, olivos, y en algunos casos flores como en en el departamento de Maipú en las UVP2 y 4.

\section{5 - EL SISTEMA ESTRUCTURANTE Y LA VISIBILIDAD COMO RECURSO TURÍSTICO}

El hombre cuando se apropia del territorio lo hace en función de satisfacer sus necesidades para su desarrollo y sobrevivencia actuando sobre el mismo condicionándolo en función de su propósito. Actividades como las productivas y el habitar conjugan un conjunto de acciones estructuradas necesarias para poder cumplimentar el objetivo propuesto y requiere de obras específicas sobre el territorio y movilidades que condicionan las características formales, funcionales y ambientales, entre otras, influyendo directamente en el carácter del Paisaje. Por lo tanto al efectuar el análisis del paisaje identificando el sistema predominante (también entendido como conjunto de acciones estructuradas ante un objetivo) que estructuró el territorio, nos está indicando justamente el conjunto de bienes, actividades y dinámicas propias del marco contextual de la época a la que corresponde el sistema, lo que influye directamente en el carácter del paisaje en estudio.

En este marco para efectuar el estudio se analizó al SISTEMA ESTRUCTURANTE del paisaje tratando de identificar en el paisaje cual es el sistema que predomina y se puede observar. De ellos seleccionamos las siguientes opciones: (A- El sistema estructurante de la vid y el Vino de la Industrialización y expansión vitivinícola; B- De la $2^{\mathrm{a}}$ modernización vitivinícola, C- De la metropolización, D- Hidráulico). Destacamos que si bien el sistema estructurante del paisaje es uno de los factores que contribuyen a las características observables del paisaje, para poder apreciarlo y analizarlo en sus diferentes escalas es fundamental el estudio de la VISIBILIDAD que se tiene de la estructura del mismo. La visibilidad del paisaje es un aspecto relevante ya que permite determinar qué área del territorio y elemento constitutivo es percibido o no, lo que es fundamental tanto en la determinación de las unidades visuales de paisaje y como en la valoración y gestión del mismo. Es por ello que en el trabajo de campo en torno a la VISIBILIDAD de la estructura del paisaje se observó si el tipo de PO nos brindaba una lectura (PANORÁMICA; INTERMEDIA; FOCALIZADA) lo que nos permite tres niveles de acercamiento de visibilidad y análisis del paisaje.

En el departamento de Maipú se analizaron 55 PO en torno al sistema estructurante del paisaje como resultante el sistema predominante observado desde $51 \mathrm{PO}$ es de la vid y el Vino de la Industrialización y expansión vitivinícola; y en segundo lugar de acuerdo a lo relevado en 4 PO es el sistema hídrico. En cambio sobre la visibilidad estructural se detectó 26 PO PANORÁMICOS; 15 INTERMEDIOS; y 14 FOCALIZADOS. En el departamento de Luján de Cuyo la cantidad total de PO analizados es de 30 detectándose tres tipos de sistemas estructurantes que influyeron en el carácter del paisaje agrícola vitivinícola. En 6 PO se observó el sistema estructurante De la vid y el vino de la Industrialización y expansión vitivinícola; en $17 \mathrm{PO}$ el de la 2da modernización y $5 \mathrm{PO}$ el de la metropolización. En torno a la visibilidad estructural se detectó 19 PO PANORAMICOS; 5 PO INTERMEDIOS; 6 PO FOCALIZADOS.

Del análisis de los datos obtenidos de los dos departamentos vemos que el sistema hídrico y el de la vid y el vino estructuraron el paisaje agrícola vitivinícola en los territorios más antiguos comprendidos por las UVP2 y 4; el de la $2^{\mathrm{a}}$ modernización en los más nuevos UVP7 y 8 ; y el de la metropolización como la red de elementos y relaciones que está afectando el carácter del paisaje 
producido por el sistema de la vid y el vino de la industrialización y expansión vitivinícola, siendo los dos sistemas los que actualmente se integran en la UVP1. Por otra parte, si analizamos el sistema estructurante del paisaje en relación a la visibilidad nos permite pensarlo como una herramienta de lectura para detectar la banalización y/o el deterioro del mismo, en donde los tres niveles de visibilidad del punto de observación son fundamentales para graduar la lectura y análisis del problema.

Figura 5. Vista del punto de observación PO 40 Ruta 60 Y Nazar Departamento de Maipú. En el mismo se observa una visibilidad estructural focalizada.

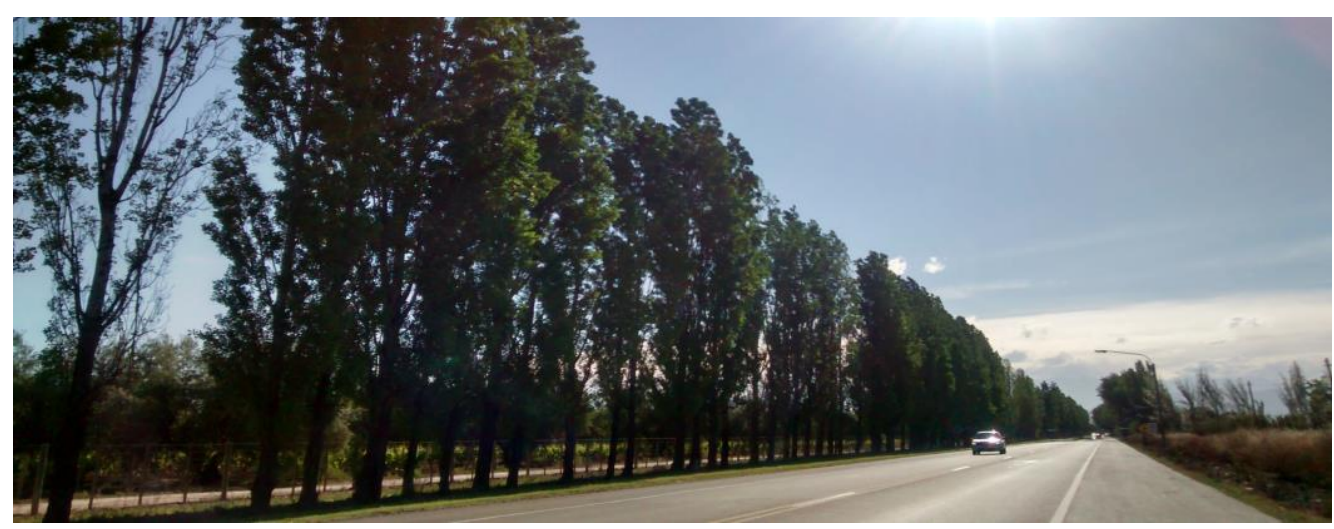

Fuente: Archivo personal del autor - INCIHUSA - CONICET, fotos tomada en el 2017.

\section{6- LA CALIDAD VISUAL Y LA INTERVISIBILIDAD COMO RECURSO TURÍSTICO.}

Destacamos que el valor de la calidad visual del paisaje es un recurso de alta potencialidad para una gestión y planificación de un turismo sustentable del paisaje y desarrollo local. Esta última se encuentra en estrecha relación con la intervisibilidad entre los PO del paisaje para escoger cuáles son las zonas más visibles o menos visibles lo que es fundamental en las labores de gestión y su aprovechamiento como recurso colectivo. Para efectuar el análisis de la CALIDAD VISUAL DEL PAISAJE se tuvo en cuenta las siguientes variables: La Morfología del terreno; Vegetación; Agua; Color; Contexto escénico; Rareza; Actuaciones humanas; Clase de calidad visual (CLASE A: 19-35ALTA, CLASE B: 12-18-MEDIA, CLASE C: 4-11-BAJA). La INTERVISIBILIDAD: Intervisibilidad entre $\mathrm{PO}(\mathrm{SI} / \mathrm{NO})$

La relación entre la imagen del paisaje del entorno inmediato (oasis agrícola) en el centro con la del fondo visual de la montaña al oeste y de llano hacia el este, hacen que las UVP de los departamentos posean un juego de relaciones visuales que le otorgan en Maipú calidad visual ALTA como se puede observar en los $51 \mathrm{PO}$ de un total de $55 \mathrm{PO}$ en el departamento. Lo mismo pasa en Luján de Cuyo que del total de 30 PO del departamento 24 PO poseen calidad visual Alta. Esta fortaleza adquiere mayor riqueza si el punto de observación es panorámico, intermedio o focalizado y si existe intervisibilidad entre los puntos de observación. Destacamos que para definir la calidad visual se evaluó en cada punto de observación: 
Tabla 2

Variables e indicadores para definir la calidad visual en cada PO

\begin{tabular}{|c|c|}
\hline Variable & Puntaje Numérico - Rango valorativo - Indicador \\
\hline $\begin{array}{l}\text { Morfología } \\
\text { del terreno }\end{array}$ & $\begin{array}{l}\text { 5-ALTA-relieve montañoso, marcado y prominente. } \\
\text { 3-MEDIA-relieve montañoso, no muy marcado ni prominente. } \\
\text { 1-BAJA-relieve llano, con colinas suaves, fondo de valles). }\end{array}$ \\
\hline Vegetación & $\begin{array}{l}\text { 5-ALTA-Gran variedad de tipo de vegetación. } \\
\text { 3-MEDIA-Alguna variedad. } \\
\text { 1-BAJA-poco o ninguna variedad. }\end{array}$ \\
\hline Agua & $\begin{array}{l}\text { 5-ALTA-factor dominante limpia y clara. } \\
\text { 3-MEDIA- no dominante en el paisaje. } \\
\text { 0-BAJA- ausente o inapreciable. }\end{array}$ \\
\hline Color & $\begin{array}{l}\text { 5-ALTA-combinaciones de color intensas y variadas, contrastes. } \\
\text { 3-MEDIA-alguna variedad en la mezcla de color y contrastes. } \\
\text { 1-BAJA-muy poca variación de color y contraste. }\end{array}$ \\
\hline $\begin{array}{l}\text { Contexto } \\
\text { escénico }\end{array}$ & $\begin{array}{l}\text { 5-ALTA-el paisaje circundante potencia la calidad visual del conjunto. } \\
\text { 3-MEDIO-incrementa moderadamente la calidad visual del conjunto. } \\
\text { 0-BAJA-no ejerce influencia en la calidad del conjunto. }\end{array}$ \\
\hline Rareza & $\begin{array}{l}\text { (5-ALTA-único o muy raro en la región; 3-MEDIA-posibilidad de contemplar fauna y } \\
\text { vegetación excepcional; 1-BAJA-característicos aunque similar a otros en la región. }\end{array}$ \\
\hline $\begin{array}{l}\text { Actuaciones } \\
\text { humanas }\end{array}$ & $\begin{array}{l}\text { 5-ALTA-libre de actuaciones estéticamente no deseadas o que no lo afectan. } \\
\text { 2-MEDIA-calidad escénica afectada por modificaciones sin armonía o intensas y/o } \\
\text { extensas. } \\
\text { 0-BAJA-modificaciones intensas y/o extensas que reducen o anulan la calidad } \\
\text { escénica. }\end{array}$ \\
\hline
\end{tabular}

Fuente: Elaboración propia del autor

De acuerdo al puntaje numérico obtenido de la información relevada en los puntos de observación es si correspondía la calidad visual a un valor Clase $A, B$ o $C$ lo que nos permite diseñar un mapa de recursos visuales del paisaje: Clase A: ALTA integra áreas de rasgos singulares y sobresalientes. Clase B: MEDIA integra áreas cuyos rasgos poseen variedad en la forma, color, línea y textura, pero que resultan comunes en la en la región estudiada. Clase C: BAJA integra áreas con muy poca variedad en la forma, color, línea y textura.

A su vez, la calidad visual del paisaje se incrementa si existe intervisibilidad de puntos.

Efectuando una síntesis del análisis de la información obtenida desde los (PO) de las unidades de paisajes estudiadas UVP1, 2, 4, 6, 7, 8 en totalidad presentan características singulares y sobresalientes correspondientes a la clase A. Por otro lado, se observa que de acuerdo al lugar de ubicación de la Unidad visual patrimonial de Paisaje y los puntos de observación en la misma, se produce un juego de relaciones visuales entre la montaña, el valle cultivado y el llano 
del secano que son una verdadera fortaleza visual del paisaje que en la actualidad no es explotado plenamente como recurso ni contemplado en la planificación del territorio, ni como estrategias turísticas.

\section{1 - Las limitaciones visuales del paisaje de Maipú y Luján de Cuyo en torno al estudio de las Unidades Visuales Patrimoniales del Paisaje.}

Para evaluar y definir las posibles limitaciones visuales del paisaje, se analizó la DEGRADACIÓN DEL PAISAJE en sus diferentes tipos (1-Erosión, 2-Cambios de uso del suelo, 3Contaminación visual, 4-Contaminación ambiental, 5-Obras públicas, 6-Obras privadas).

De acuerdo a lo observado desde los PO observamos tres aspectos principales que están degradando el paisaje a escala departamental como en las unidades visuales patrimoniales del paisaje. En primer lugar la contaminación visual con los tendidos eléctricos y cableados aéreos, en Maipú de un total de 55 PO analizados se observó esta característica en 39PO. En Luján de Cuyo de un total de 30 PO se observó en 19PO. En segundo lugar la contaminación ambiental por los residuos en Maipú se detectó en 10PO y en Luján solo en 1PO. En tercer lugar la degradación por el cambio de uso del suelo que integra la pérdida del uso agrícola de la tierra incluyendo tanto el traspaso de uso agrícola al habitacional, como la propiedades y superficies cultivables en abandono.

No obstante haciendo un análisis pormenorizado de la problemática en cada UVP detectamos que la mayor concentración de contaminación visual se produce en zonas de mayor desarrollo urbano en la medida que se acerca a los poblados y disminuyendo la cantidad del cableado en la medida que se aleja como se puede corroborar la UVP1 posee 19 PO donde se observa esa problemática de un total de 23PO; lo mismo en UVP2 se observa desde 21PO de un total de 26 PO. Destacamos que los distritos que integran estas UVP son los más urbanizados. En cambio en la Unidad Visual Patrimonial de Paisaje hacia el Sur del Río Mendoza se observa en la UVP 7 Agrelo solo en 8 PO y en la UVP 8 Ugarteche se observa en 1PO. En cuanto a la degradación ambiental de depósito de basura se produce en los distritos más alejados pero ubicado en los bordes del Río Mendoza como en UVP2 y UVP6, como también en caminos próximos al río en la UVP4. Destacamos que la degradación en torno a la erosión también se observa en las UVP2 y 6 en la ladera del Río Mendoza. La problemática de cambio de uso del suelo se observa en las UVP que poseen zonas de interface que es el espacio de transición entre lo rural y lo urbano como la UVP1 y UVP2. No observándose en las UVP que poseen mayoría de suelo rural como la UVP6, 7 y 8. Estos tipos de patologías son clara respuesta a deficiencias de la educación de la sociedad y el compromiso ciudadano en la preservación y cuidado del medio ambiente cuyo reflejo se observa en el paisaje analizado.

Figura 6. Vista del punto de observación 57-LJ PO Acceso Sur esq. NO y Río Mza. Departamento de Luján de Cuyo. En el mismo se observa degradación ambiental de depósito de basura y erosión. 


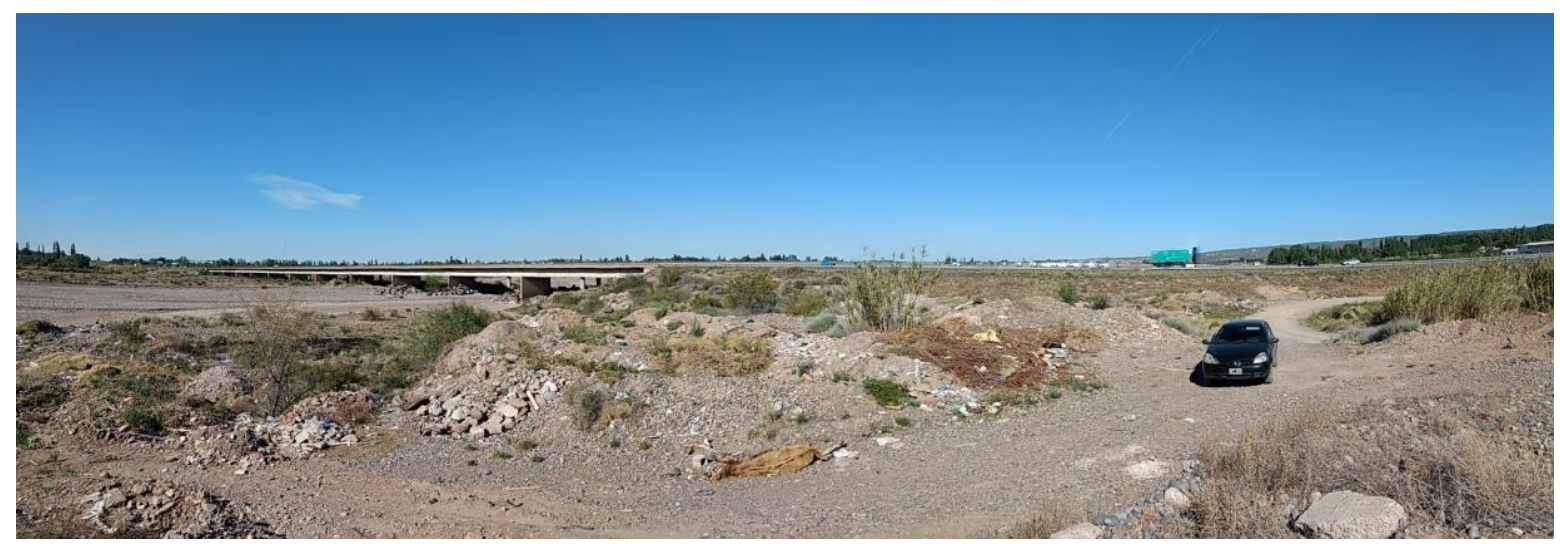

Fuente: Archivo personal - INCIHUSA - CONICET - foto tomada en el 2017

\section{7 - CONCLUSIÓN:}

En el presente trabajo se propuso efectuar un análisis de la calidad visual patrimonial en relación a la dimensión histórica del paisaje agrícola - vitivinícola del AMM con el fin de contribuir con un turismo sustentable que promueva un desarrollo local. Entendiendo por calidad visual patrimonial al grado de excelencia de los atributos visuales de las características físicas e históricas del paisaje. Para ello se centró el análisis en los departamentos de Luján de Cuyo y Maipú y se analizó la dimensión histórica del paisaje, lo que nos permitió definir las Unidades Visuales del Paisaje patrimonial poseedoras de valor histórico en las que sus características generales y usos del suelo se presentan como un potencial recurso visual turístico. También se efectuó el estudio del proceso de conformación en el tiempo como una conjunción de sistemas estructurantes y su visibilidad, ampliando su potencial turístico al comprender la calidad visual del paisaje y la fortaleza de la intervisibilidad de los puntos de observación en el paisaje.

No obstante, este potencial como recurso visual turístico posee limitaciones de acuerdo a las características paisajísticas de nuestro marco geográfico dependiendo si la observación del paisaje es focalizada, intermedia o panorámica. Es decir, se observa que el paisaje tiene un alto valor cultural e histórico y de calidad visual que los diversos actores gubernamentales como los vinculados a la educación, al turismo, los agentes inmobiliarios, como los productores no lo aprovechan en profundidad. Hacen uso de la imagen del paisaje pero no tienen en cuenta una mirada integrada y un compromiso con el paisaje como un sistema.

Esto, conduce a plantear que para observar con excelencia los atributos visuales de las características físicas e históricas del paisaje y desarrollar la calidad visual patrimonial como recurso turístico es necesario promover el reconocimiento del paisaje agrícola vitivinícola y sus elementos constitutivos como sistema integrado y como los diversos actores se beneficiarían con su cuidado y promoción. En este marco se propone aprovechar las redes de puntos de observación (PO), líneas de observación (LO) y los recorridos escénicos paisajísticos patrimoniales (REP) desde donde se pueden observar los diversos elementos constitutivos del paisaje en el territorio (edificios, sitios, ejes, áreas y áreas de valor histórico tanto público como privado), en sus tres escalas de observación focalizada, intermedia y panorámica, como recurso tanto productivo como recreativo. Pudiendo estas 
redes ser integradas a las rutas culturales y educativas con la aplicación de Tics como los códigos QR (Quick Response code) y realidad aumentada para transmitir la explicación del significado y valor histórico de una manera interpretativa e integrada.

De esta manera se considera que el reconocimiento de los valores visuales del paisaje en conjunción a la dimensión histórica no solo hace factible su aprovechamiento como recurso turístico promotor de desarrollo local, sino también permite ordenar de forma adecuada la implantación de determinados usos y actividades turísticas sustentables en el territorio. Contribuyendo de esta manera que el paisaje sea adecuadamente percibido, comprendido, apreciado, disfrutado y por consiguiente valorado. Lo que beneficia su protección y contribuye en la construcción de la identidad en relación al territorio de la sociedad.

\section{8 - BIBLIOGRAFÍA DE REFERENCIA}

Abraham, E. (2000). Recursos y problemas ambientales de la provincia de Mendoza. En: Abraham, E. y Rodríguez Martínez. F. (eds.). Argentina: recursos y problemas ambientales de la zona árida. Provincias de Mendoza, San Juan y La Rioja. Junta de Gobierno de Andalucía, Universidades y Centros de Investigación de la Región Andina Argentina. Mendoza, s/d

Cirvini, S. \& Manzini Marchesi, L. (2012). El paisaje vitivinícola. Identificación y caracterización. Mendoza, Argentina. En revista de Historia Americana y Argentina, N. 47, 101-131

Cruz Pérez, L. \& Español Echániz, I. (2009). El paisaje. De la percepción a la gestión. España: Ediciones Liteam.

Instituto Nacional de Vitivinicultura (2019). Informe Región Centro - Oeste provincia Mendoza área centro (Departamentos: Godoy Cruz, Guaymallén, Luján de Cuyo y Maipú). Elaborado por Subgerencia de Estadísticas y Asuntos Técnicos Internacionales Instituto Nacional de Vitivinicultura Junio 2019. Disponible en: https://www.argentina.gob.ar/sites/default/files/evolucion_de_superficie_zona_centro. pdf. Consultado en 13/2/2020 a las 12:40

Manzini Marchesi, L. (2018). Momentos críticos en la conformación del territorio que influyeron en la degradación del paisaje vitivinícola del Área Metropolitana de Mendoza. (1561 - 2010). En Boletín de Estudios Geográficos, N. 109, 93 - 138

Manzini Marchesi, L. (2017). Las viviendas de la extraterritorialidad y su influencia en el paisaje cultural vitivinícola del Área Metropolitana de Mendoza. En ACE: Architecture, City and Environment, vol. 12, N. 35, Octubre 2017, 71-102

Manzini Marchesi, L. \& Gómez Voltán, José. (2019). TEÁNGULO. Manual de uso. Disponible en: https://patrimonioenlamira.files.wordpress.com/2020/05/tec381ngulo-manual-de-uso-1.pdf. Consultado el 15/10/2020 a las 21:50

Martínez De Pisón, E. (2007). Paisaje cultura y territorio. En NOGUE, J (ed). La construcción social del paisaje. Madrid, Editorial Biblioteca Nueva, 325-337

Martínez de Pisón, E. \& Ortega Cantero, N. (Eds.). (2010). El Paisaje valores e identidades. Madrid: Ediciones de la Universidad Autónoma de Madrid y Fundación Duques de Soria.

Mata Olmos, R. (2008). El Paisaje, Patrimonio y Recurso Para El Desarrollo Territorial Sostenible. 
Conocimiento y Acción Pública. En Revista ARBOR Ciencia, Pensamiento y Cultura CLXXXIV. N. 729, 155-172.

Muñoz - Pedreros, A. (2017). El paisaje visual: Un recurso importante y pobremente conservado.

En Revista Ambiente \& Sociedade. Sao Paulo V. XX, N. 1, 167 - 186.

Montoya Ayala, R. \& otros (2003). Valoración de la calidad y fragilidad visual del paisaje en el valle de Zapotitlán de las salinas, Puebla (México). En Boletín de la A.G.E. N.35, 2003, 123- 136.

Navarro Bello, G. (2004). Una aproximación al paisaje como patrimonio cultural, identidad y constructo mental de una sociedad. Apuntes para la búsqueda de invariantes que determinen la patrimonialidad de un paisaje. En Revista Electrónica DU \& P Revista de Diseño Urbano y Paisaje. N1(1), s/d

Secretaría de Ambiente y Ordenamiento Territorial. Agencia Provincial de Ordenamiento Territorial. Gobierno de Mendoza (2017). PLAN PROVINCIAL DE ORDENAMIENTO TERRITORIAL (PPOT) Ley provincial $\quad \mathrm{N}^{\circ} 8999$ Disponible en: https://www.legislaturamendoza.gov.ar/wpcontent/uploads/2017/12/4_8999_plan_ordenamiento_territorial.pdf. Consultado el $13 / 2 / 2020$ a las $13: 00$

i LORENA MANZINI MARCHESI: Arquitecta (Universidad de Mendoza, 1999), Doctora en Arquitectura (Universidad de Mendoza, 2009), Diplomada de Historia en Mendoza (Universidad de Congreso, Mendoza, 2004). Investigadora Adjunta del CONICET, INCIHUSA (Instituto de Ciencias Humanas, Sociales y Ambientales), CCT - Mendoza (Centro Científico Tecnológico Conicet en Mendoza). Coordinadora del Grupo de investigación Historia y Conservación Patrimonial del INCIHUSA - CONICET. Miembro del Consejo Provincial de Patrimonio de la Provincia de Mendoza y de ICOMOS Argentina.

ii En el presente artículo se presentan resultados de la investigación de base y aplicada llevada a cabo en el marco del plan bianual de labores del CONICET titulada "LA DIMENSIÓN PATRIMONIAL DEL PAISAJE VITIVINÍCOLA Y EL DESARROLLO SUSTENTABLE. DIAGNÓSTICO Y LINEAMIENTOS ESTRATÉGICOS. EI caso de los departamentos de Luján de Cuyo y Maipú del AMM."efectuado desde 2016 al 2017 en el INCIHUSA - CONICET.

iii Esta realidad es denunciada por la prensa como las notas publicadas en el Diario los Andes del 30 de enero del 2016 titulada "Regalaron toda la producción de frutas" en https://losandes.com.ar/article/view?slug=regalaron-toda-laproduccion-de-frutas y el 12 de febrero del mismo año en la que se tituló "Ahogados por la crisis, productores del Sur mendocino regalan la cosecha de frutas" https://losandes.com.ar/article/view?slug=ahogados-por-la-crisis-productores-del-surmendocino-regalan-la-cosecha-de-frutas.(Última Fecha de consulta de los links el 19 de septiembre de 2017).

iv ¿Por qué la necesidad de crear herramientas científicas de Eco-amigables? Para construir un mundo sustentable se requiere de un profundo compromiso en la búsqueda de un cambio de paradigma de vida que contribuya en proteger la calidad ambiental del planeta tierra. Para ello desde nuestra área de acción, la ciencia, podemos tomar decisiones que siembren un camino de innovación en sus prácticas que ayuden a conservar los recursos naturales y que nos permita desempeñar nuestra labor y obtener resultados con rigor científico de un modo sustentable. A su vez las herramientas diseñadas con estas características son de ínfimo costo, lo que es beneficioso para investigaciones con escaso presupuesto, además no requieren de un alto nivel de especialización para su empleo y poseen potencialidades múltiples que exceden los fines científicos, como por ejemplo otorgan mayor seguridad en los trabajos de campo al no ser objetos valiosos económicamente, lo que es muy importante cuando las campañas se efectúan a campo abierto.

V Para ampliar sobre las características históricas arquitectónicas de las Unidades Visuales Patrimoniales consultar MANZINI (2018) 